\title{
New Perspectives of Musicality Analysis of Schumann's Childhood
}

\author{
$\operatorname{Lin} \mathrm{Su}^{1, \mathrm{a}}$ \\ ${ }^{1}$ Shaanxi Xueqian Normal University, Xi'an, 710000, China \\ ${ }^{\mathrm{a}}$ email
}

Keywords: Schumann's Childhood, Musicality analysis

\begin{abstract}
This paper analyzes the background, style and creative features of Schuhmann's piano works Childhood and sums up the unique and distinctive musicality of the works. We can get a better understanding from the angle of both appreciation and performance. In addition to my practical playing experience, I believe I can interpret the musical nature of Childhood from a new angle of view.
\end{abstract}

In the early nineteenth Century, Schuhmann, one of Germany's most representative romantic composers, was a composer who successfully transformed pure emotions into pure sounds. Literature, poetry, fiction and drama gives inspiration and the source of his music creation content, its music magazine and served as music critic work strengthened his confidence to the music creation direction, in the attack in music and certainly vulgar mediocre and enhance excellent composers for music concept of high perspicacity. He worshiped and praised Bach, although he was criticized as "unbalanced use of counterpoint", but the "fugue" spirit embodied in his works is full of infinite vitality. Although Lester had never played Lester's "Fantasia on C major" written by Schuhmann, it was enough to see Schuhmann's admiration for him. Although Schuhmann did not use Beethoven's expansion theme in his writing, he adopted the theme of Beethoven's music and endowed the romantic with the poetry. After almost forgotten Schubert manuscripts were discovered in the Schuhmann accident, he made the first "Vienna Carnival" is full of joy and enthusiasm, caprice and wild romantic color.

\section{Musicality Analysis from the Perspective of Composing Background}

The work of Childhood was based on Hoffman Schuhmann (Hoffmann) of the "calota style fantasy", in 1838 the creation of the piano suite, is dedicated to Schuhmann love lover Clara song, by Clara childhood memories, entrusted with a strong sense of love, with the composer heart affection and care, I hope people who love each other forever remember the wonderful childhood. Seemingly simple 13 ditty, but behind it contains a profound meaning of love and no words of musical mood. Schuhmann really put his inner feelings and language into the music, which is a natural and true outpouring. Schuhmann tried to dig into the children's hearts and show them what they were going through. This work is not only a brief description of the lives of children, but also evokes memories of childhood. Schuhmann once admitted: "before I finished these works, these titles never appeared in my mind."." You can see this 13 song title is added later, the title of the music: 1, "strange country and people", four note calm interspersed with unstable dot notes, showing the kids feel fresh and curious to hear the story of exotic mood. 2, the strange story, weird mutant rhythm, seems to see the children after listening to strange stories after the incredible expression. 3, "hide and seek" shows the children bouncing and dancing, you hide me, hide, chase the game lively scene. 4, "children's request", the children eager eyes, looked at the people's response to their request, hope to. A counterpoint to the inner voice that shows the communication between an adult and a child. 5, "incomparable happiness", a small reward can make the children very happy, happy, loud and continuous jump ups and downs, as if cheerful mood, excited, unable to curb the satisfaction and joy. 6, the big event, for the children, solemn and serious national events happen, there are fixed rhythm chords and left hand eight degrees 
of strong pace to quiet the children. 7, "dream song", classic and dreamlike music artistic conception, the melody is slow and melodious, slightly sad and nostalgic feelings, Wan Wan dao. 8, "beside the fire" shows the children sitting around the fire talking and laughing, warm and harmonious family scene. 9, "ride a horse", the children up and down in the amusement park and ride a horse when the heart is full of pride, happy scenes, with a syncopated rhythm reflects the sense of frustration of Trojan horse. 10, "too serious", the performance of children innocent, innocent, serious thinking expression. 11, "shock", in the face of fear when the inner experience, seemingly calm down a semitone scale sudden unexpected strange rhythm, the children are afraid of fright picture performance. 12, "children go to sleep", alternating hands slow, the first eight, sixteen rhythm, just like the children's sleep after the faint wheezing. 13, "the poet's words", the last expression of the poet's tone to describe the childhood has gone to the sad and melancholy. These titles are very close to the content. As long as you look at the title, you can have a rough idea of the content of the music. Some of the wonderful pieces are often played individually, such as "Fantasia" and so on. Schuhmann said: "no work, like" childhood scene ", is really out of my heart." The whole works have vivid description of psychology, accurate image description, moving and interesting.

\section{Musicality Analysis from the Perspective of Music Style}

This piece belongs to the romantic style of music, both in form, in subject matter and in content. Before Schubert's "impromptu", Mendelsohn's "Songs without words", they can play one of the song, while Schuhmann's divertimento is a complete works, generally do not separate playing. And Lester's "symphonic poem", only one movement and with a title, a short and free. Schuhmann was influenced by Schubert, vocal divertimento usually combined some of his short piano musical set according to a certain order, and a name for it, which each have a small independent descriptive title. The works "childhood scene" also have certain logical relation in the order arrangement. It should be said that Schuhmann's writing style is consistent. Because he is extremely sensitive personality and Clara's unusual love experience makes him pay more attention to mining personal inner life and emotional world, more emphasis on performance experience, vision, fantasy and passion. Such enthusiasm among Schuhmann's works has rarely been surpassed by composers in the nineteenth Century. "Childhood scene," this is Schuhmann's letter to Clara, said, once again, back to childhood mood, wrote 30 or so ditty, selected 12, plus "childhood scene" title. When it was published, Schuhmann added another one and became the 13. It was Schuhmann who recalled his wife Clara's childhood, ignited his inner feelings, and inspired his inspiration. A series of brief, vivid thoughts flashed forth. In addition, the creation of Schuhmann's "Butterfly" derived from Jean Paul (Jean Paul) of the novel "young years", "symphonic Etudes" is borrowed from his teacher at the Vic, Schuhmann draw inspiration and material at the same time from the music of others or literary works, also attaches great importance to the work the heart depicts. Not only has the fantasy, and improvisation, such as Schuhmann borrowed from Hoffman (Hoffmann) of the "Fantasia collection" (Phantasiestucke) as the name, the creation of "Fantasia collection" (Op.12), one of the most popular second song "impulse" (Aufschwung) burst of enthusiasm is enough to impress the audience, he tried to create an illusion of excitement and impromptu uninterrupted atmosphere. "I Chrysler" although not a song to audience understanding and acceptance of works, Schuhmann borrowed Hoffman's masterpiece "John Chrysler" in a fictional name of Chrysler, work is not interested in its structure, but the character's nuanced portrayal of. Thus, Schuhmann created a piano divertimento in this form, and use a variety of literary poems and other material, makes the rich and colorful music image, music content is more emotional cover and contain everything, sincere and moving. This is the soul of artistic creation. It selects classical themes, uses reasonable forms, and uses advanced techniques to inject true emotions. 


\section{Musicality Analysis from the Perspective of Creative Features}

Schuhmann's melodies are short and refined, but lyrical and flexible. For example, the first "strange country and people" Melody began with six degrees of ups and downs, and then gradually down, first of all to give people a new feeling, and then produce a soft and close feeling. The seventh song "fantasy" melody is so cherished, unforgettable, before and after the fantastic melody lines appeared eight times, but lead a person to endless aftertastes. In addition, the interweaving and merging of the left hand polyphony parts, a seamless whole, is full of the power and poetry of unlimited expansion. The first fifth "happiness" in the use of writing techniques, the left hand right hand repeated treble bass melody lines, seems both single and interesting, a lively picture. In tonal, almost every use of capital transfer, which not only makes the work of changing colors, but also promote the development of the thought of music. The whole song has a unified tonal layout, the first major in G, and the next twelve are in parallel, minor, minor and minor. There is a certain logical relationship between the music, and the thirteen tunes are closely linked together. Schuhmann not only broke through the vocabulary of traditional harmony, but also full of creativity. He broke the fixed connection mode of $\mathrm{T}$ and $\mathrm{S}$, traditional $\mathrm{D}$, enhanced the dissonance of harmony, in addition to the weakening of the main function, also is to connect mode, subordinates also used nine chord cadence to the main connection, the ultimate pursuit of innovation in this series are derived from Schuhmann's expression the sound of the. In this thirteen songs, most of the use of a single three individual form, Rondo and single music section, visible Schuhmann prefer small form, it is the only short ditty let the audience impressed, easy to accept gifted with an extraordinary retentive memory, and understanding, not long winded dull feeling, but feel fresh and natural, flowing into it the hearts of the audience.

\section{Musicality Analysis from the Perspective of Artistic Characteristics}

Whether Schuhmann in his piano or piano, not just by the title to express a sound pattern, the most important thing is to evoke a mood music outside the show in front of the audience and the poetic picture. The reason he transplanted the form of literature into music was a typical example of the romantic period. Although Schuhmann admits he usually writes music before adding headlines, he still shows his romantic music attitude. Only from the "Kinderszenen" among the thirteen songs that his music is sometimes gentle and delicate, and sometimes wild enthusiasm, sometimes whimsical, sometimes quiet, sometimes full of fantasy, and weird. That is to say, to represent the many layers of his nature fully and fully in music. Almost every ditty has subtle counterpoint and Fugue, which is the deep influence Bach has on Schuhmann's style. Schuhmann has been studying the music of Beethoven and Bach and has been urging others to do so. One of the young musicians he gave advice is: "qinxuekulian outstanding masters of the Fugue, especially John Sebastian Bach. You'll be a great musician with your regular daily bread." Schuhmann's piano seems to be short, but it is not easy to play, because of its melody and singing line ups and downs, fusion and internal voice texture and Fugue staggered, bold breakthrough and innovation of harmony, the rhythm of the music emotion change unpredictably, nuanced. The music of the complex does not represent the composer virtuoso to conquer the audience, either appreciate or play, do not feel the slightest skills show, Schuhmann used all piano vocabulary, not deep understanding and accurate grasp of the music ontology of musical ability, it is difficult to interpret in place.

\section{Conclusion}

In a word, musicality runs through Schuhmann's music from beginning to end, pure and full of color. Schuhmann is such a natural and calm although there is no Beethoven Baroque composer Bach and the classical period so prominent, nor romantic Chopin so much attention, but the charm of Schuhmann's unique music has increasingly been people's love and concern, more and more people to study music and play the music of Schuhmann. Feel the romantic music Pioneer music world. To achieve a scene through art creation, and environment harmony is not the highest realm of music 
creation. If we can inspire some thoughts and get some inspiration through Schuhmann's piano works, we will be gratified and satisfied, and we will continue to work hard at the same time.

\section{Acknowledgements}

The author chaired Scientific Research Subject of Shaanxi Xueqian Normal University in 2015 named Research on Practice Research on Piano Training in Preschool Education Major in Normal Universities. The author chaired Research Project of Teaching Reform of Shaanxi Xueqian Normal University named Applications Research of Piano Documents in Piano Teaching (Grant No.15JG033Y). The author chaired Research Project of Key Theoretic and Realistic Problems in Social Scientific Cycle of Shaanxi in 2016 named Research on Application Practice of Piano Documents.

\section{References}

[1] Tian Tian, Analysis of Music Style and Works of Schuhmann Piano Divertimento The scene of Childhood [J]. Journal of Qiqihar University (Philosophy \& Social Science Edition), 2015(10): 155-157.

[2] Zhang Yi, Art Song Comparison between Schubert and Schumann-taking Narration Subject as Example [J]. Journal of Xiangnan University, 2015, 36(3): 75-80+85.

[3] Xu Chi, an analysis of the Criticism of music of the Composer Robert Schumann [J]. Education Modernization, 2015(9): 125-127.

[4] Wu Yuanyuan, Music Text Analysis of Piano Cycle of Schumann's Childhood Scene [J]. Journal of Weinan Normal University, 2013, 28(4): 86-92. 